See Article page 1436.

\section{Commentary: Dissecting out the root of the matter-how much to intervene in type A dissection}

\author{
Eltayeb Mohamed Ahmed, MBBS, and \\ Edward P. Chen, MD
}

Type A acute aortic dissection (TAAAD) is a lethal condition carrying a high mortality rate without surgical intervention. Operative outcomes and long-term survival have improved significantly over the last 2 decades; however, aortic intervention rates after initial operative repair remain high. ${ }^{1}$ Reintervention after initial TAAAD repair includes both proximal and distal aortic procedures, with proximal procedures typically being indicated for aortic insufficiency or aortic root dilatation. The primary risk factors that have been identified for reoperation include young age, connective tissue disorders, aortic root dilatation, and degree of preoperative aortic insufficiency. ${ }^{2-5}$ There remains a poor understanding of specific genetic sequences and their potential impact on the risk of subsequent reintervention and long-term survival.

In this report, Norton and colleagues ${ }^{6}$ performed whole exome sequencing of 11 genes in 175 patients presenting with aortic dissection over a 30 -year period. On the basis of variation in these genes, patients were divided into 2 groups: pathogenic $(\mathrm{n}=31)$ and normal $(\mathrm{n}=141)$, with the most common pathogenic variants being in the FBN1 gene. Ultimately, the patients with pathogenic variants were younger and had higher aortic reintervention rates. Having a pathogenic variant was found to be an independent risk factor for an aortic root reoperation (hazard ratio, 13.1; 95\% confidence interval, 3.4-51.1), but not for arch reintervention (hazard ratio, 3.8; 95\% confidence interval, 0.7-21.3). Despite this higher reintervention rate, patients in the pathogenic group had long-term survival similar to that of their normal counterparts. The work presented by the University of Michigan group is interesting and deepens

\footnotetext{
From the Division of Cardiothoracic Surgery, Emory University, Atlanta, Ga. Disclosures: Authors have nothing to disclose with regard to commercial support. Received for publication Feb 3, 2020; accepted for publication Feb 4, 2020; available ahead of print Feb 14, 2020.

Address for reprints: Edward P. Chen, MD, Division of Cardiothoracic Surgery, Emory School of Medicine, Emory Clinic, 5665 Peachtree Dunwoody Road, Suite 200, Atlanta, GA 30342 (E-mail: epchen@ emory.edu).

J Thorac Cardiovasc Surg 2021;162:1449-50

$0022-5223 / \$ 36.00$

Copyright (C) 2020 by The American Association for Thoracic Surgery https://doi.org/10.1016/j.jtcvs.2020.02.008
}

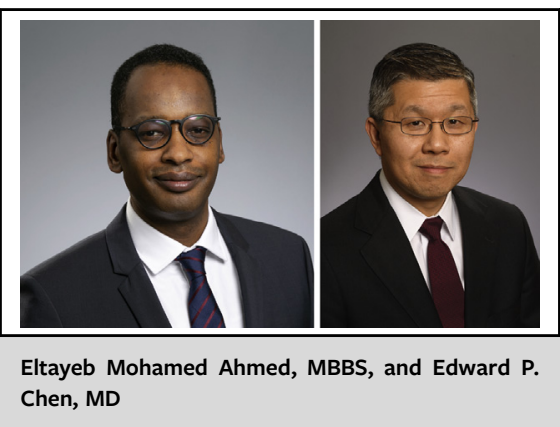

CENTRAL MESSAGE

In patients with genetic aortic syndromes presenting with TAAAD, an aggressive approach in the management of the aortic root is more warranted than aggressive arch reconstruction.

our understanding of risk stratification of reintervention after initial TAAAD repair.

However, it is important to note the limitations of this study, which include a small sample of patients in the pathogenic group, with three-quarters of the variants being associated with a single gene. Furthermore, whole exome sequencing can only be performed postoperatively in patients with TAAAD, which limits the applicability of the study findings. In addition, there appears to be a selection bias toward a tendency to perform root replacement in patients with suspected connective tissue disease, because the pathogenic group was more likely to have had a root replacement than the normal group ( $73 \%$ vs $35 \%$ ), whereas no difference was detected in the rate of arch repair between groups. Last, one-third of the initial cases were performed at other institutions, so the operative indications for initial root replacement and arch intervention are somewhat unclear.

We congratulate the University of Michigan group on the eloquently presented and important findings of this study. ${ }^{6}$ We look forward to future similar studies for identifying more reliable and sophisticated stratification tools beyond the gross anatomic findings at the time of surgery in patients presenting with TAAAD to help guide operative intervention.

\section{References}

1. Pugliese P, Pessotto R, Santini F, Montalbano G, Luciani GB, Mazzucco A. Risk of late reoperations in patients with acute type A aortic dissection: impact of a more radical surgical approach. Eur J Cardiothorac Surg. 1998;13:576-81.

2. Pan E, Gudbjartsson T, Ahlsson A, Fuglsang S, Geirsson A, Hansson EC, et al. Low rate of reoperations after acute type A aortic dissection repair from The Nordic Consortium Registry. J Thorac Cardiovasc Surg. 2018; 156:939-48. 
3. Geirsson A, Bavaria JE, Swarr D, Keane MG, Woo YJ, Szeto WY, et al. Fate of the residual distal and proximal aorta after acute type a dissection repair using a contemporary surgical reconstruction algorithm. Ann Thorac Surg. 2007;84:1955-64.

4. Rylski B. To replace or not to replace: that is the question. Eur J Cardiothorac Surg. 2016;50:239-40.
5. Leshnower BG, Chen EP. When and how to replace the aortic root in type A aortic dissection. Ann Cardiothorac Surg. 2016;5:377-82.

6. Norton EL, Hornsby WE, Wu X, Wolford B, Graham S, Willer CJ, et al. Aortic progression and reintervention in patients with pathogenic variants following a thoracic aortic dissection. J Thorac Cardiovasc Surg. 2021;162:1436-48.e6.
See Article page 1436.

\section{Commentary: Genetic variants in thoracic aortic disease - the root of all evil?}

\author{
Gal Levy, MD, and Abe DeAnda, Jr, MD
}

There are currently 37 known genetic variants or mutations associated with thoracic aortic disease, as was most recently summarized by Vinholo and colleagues, ${ }^{1}$ and this total may be the tip of the iceberg. Molecular genetics bolsters the ever-expanding catalogue of culprit genes that contribute to this disease and provide the potential of personalized care to individuals suffering from aortic disease. In this current study in the Journal, Yang and colleagues ${ }^{2}$ present a retrospective study comparing the operative treatment strategies for acute aortic dissection with attention to those genetic variants that may require aggressive intervention. Recognizing that genomic variants had a much greater reintervention rate after initial surgery than normal variants, they suggest aggressive root replacement and similar arch management be considered in pathogenic variant carriers at initial repair. This concept enables the idea of tailoring aortic care in a typically silent disease with lethal potential.

As noted by the authors, at the time of the initial aortic event, there is a lack of management guidelines for patients with genetic variants. This should not be surprising, as there is, for the patients in this study, a lack of recognition of patients with genetic variants at the time of presentation, since the authors selected acute type A aortic dissections as their

From the Division of Cardiovascular and Thoracic Surgery, UTMB-Galveston, Galveston, Tex.

Disclosures: Authors have nothing to disclose with regard to commercial support.

Received for publication Feb 14, 2020; accepted for publication Feb 15, 2020; available ahead of print Feb 21, 2020.

Address for reprints: Abe DeAnda, Jr, MD, Division of Cardiothoracic Surgery, UTMB-Galveston, 301 University Blvd, Galveston, TX 77551 (E-mail: abdeanda@utmb.edu).

J Thorac Cardiovasc Surg 2021;162:1450-1

$0022-5223 / \$ 36.00$

Copyright (c) 2020 by The American Association for Thoracic Surgery

https://doi.org/10.1016/j.jtcvs.2020.02.066
Check for updates

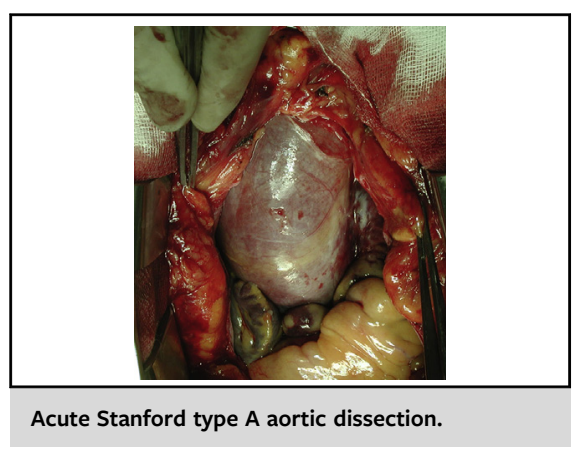

CENTRAL MESSAGE

Preoperative recognition of ge-

netic variants associated with

aortic disease may potentially

alter the surgical management of

these patients.

study cohort. If it were possible to provide the genetic information before taking the patient to the operation, the platform of genetic variant aortic disease would be transformed and the treatment algorithm would be tailored to the needs of this patient population. For patients with aneurysmal disease and/or familial thoracic aortic disease syndromes, this approach would be easier. Given the limitations of preoperative emergent genetic testing, one should hesitate to assume that more aggressive treatment should be applied universally to patients with type A dissections.

The pathogenic group in this study showed a predominance of younger, non-sex dominant, normotensive phenotypes. Beyond that, there are few identifying characters to clearly denote the pathogenic group from the benign group without knowing in advance a history of Loeys-Dietz, Ehlers-Danlos, or Marfan or a family history suggesting familial genetic mutation. The suggestion of aggressive root replacement in patients younger, without smoking history or hypertension is not without merit, considering that the data here identify this group as requiring additional procedures to address the root 